\title{
Ambient Information Visualisation and Visitors' Technology Acceptance of Mixed Reality in Museums
}

\author{
Ramy Hammady ${ }^{1}$, Minhua $\mathrm{Ma}^{2}$, Carl Strathearn ${ }^{3}$ \\ School of Computing and Digital Technologies, Staffordshire University, Stoke-on-Trent, United Kingdom \\ 1 ramy.hammady@ research.staffs.ac.uk \\ 2 m.malstaffs.ac.uk \\ 3 carl.strathearn@research.staffs.ac.uk
}

\begin{abstract}
:
The visualisation of historical information and storytelling in museums is a crucial process for transferring knowledge by directly and simplistically engaging the museum audience. Until recently, technological limitations meant museums were limited to 2D and 3D screen-based information displays. However, advancements in Mixed reality (MR) devices permit the propagation of a virtual overlay that amalgamates both real-world and virtual environments into a single spectrum. These holographical devices project a 3D space around the user which can be augmented with virtual artefacts, thus potentially changing the traditional museum visitor experience. Few research studies focus on utilising this virtual space to generate objects that do not visually inhibit or distract the operator. Therefore, this paper aims to introduce the Ambient Information Visualisation Concept (AIVC) as a new form of storytelling, which can enhance the communication and interactivity between museum visitors and exhibits by measuring and sustaining an optimum spatial environment around the user.

Furthermore, this paper investigates the perceptual influences of AIVC on the users' level of engagement in the museum. This research paper utilises the Microsoft HoloLens, which is one of the most cutting-edge imagining technologies available to date, in order to deploy the AIVC in a historical storytelling scene 'The Battle' in the Egyptian department at The Manchester Museum. This research further seeks to measure the user acceptance of the MR prototype by adopting the Technology Acceptance Model (TAM). The operational approaches investigated in this study include; personal innovativeness (PI), enjoyment (ENJ), usefulness (USF), ease of use (EOU) and willingness of future use (WFU). The population sampling methodology utilised 47 participants from the museum's daily visitors. Results of this research indicate that the willingness of future usage construct is the primary outcome of this study, followed by the usefulness factor. Further findings conclude that the majority of users found this technology highly engaging and easy to use. The combination of the proposed system and AIVC in museum storytelling has extensive applications in museums, galleries and cultural heritage places to enhance the visitor experience.
\end{abstract}

Keywords: Mixed Reality; Storytelling; Visitor Acceptance; Museum; HMDs; Ambient information visualisation; Microsoft HoloLens.

\section{Introduction}

Information visualisation methods are deployed in museums to engage a multicultural audience with variable backgrounds and experiences. For instance, Casual Information (CI) [2] is a guidance process utilised in public environments such as museums and art galleries to aid in the acknowledgement and exploration of information. Furthermore, virtual environments such as websites and mobile applications utilise a similar instructional technique [3]. However, the ambient information visualisation tool has a more substantial effect on public spaces as it is highly dynamic, interactive and accessible to the user [4]. The ambient visualisation methodology broke the boundaries of the traditional video screen approach and presented the observer with a highly immersive, engaging and visually appealing display. Recently, museums and public spaces have sought to implement digital technologies which can deliver dynamic, contextual and multimodal information systems [5].

These digital image systems deliver interactive media that encourage various activities from visitors in the museum environment. This technological approach can substantially enhance the traditional museum experience and promote a higher level of visitor engagement in museums [6]. Such user activities may include playing games like treasure hunts [7], 'Horus' [8], 'Intrigue at the museum' [9] or the collection of souvenirs and photos [10]. This interactive approach is intrinsic in enhancing the overall museum experience as the majority of visitors seek highly entertaining and engaging attractions [6] [11]. These statistics made museums compete for visitors by introducing new incentives and engaging solutions to avoid disinterest in the museum/exhibit [6]. 
Museums are predominantly educational environments; they offer a safe space to explore, learn and reflect on historical antiquities from around the world[12]. MR devices have contributed to increasing interactive ambient visualisations in museum environments. Since the development of MR platforms in museums, the potentiality for generating a greater engaging and visceral visitor experience has substantially increased. The majority of MR systems applied in museums amalgamate physical and digital objects to reshape the conventional museum experience [13] [14]. MR is a vital tool in visualising ambient information retrieval as it displays museum notifications in a more accessible manner than the traditional wall-mounted displays. The introduction of MR holographical technologies in museum environments has increased the potentiality for developing spatial applications. Previous versions of augmented reality headsets had spatial limitations due to a fixed depth map around the user.

However, contemporary holographical devices permit the user to visualise a relative convex space encompassing them; this area is equipable with various virtual objects and artefacts. The holographic spectrum interlinks with the physical world; this process can disrupt user equilibrium during virtualised interactions. Few scholars embrace this approach [15] [16] [17]. However, these researchers primarily focused on scenes that present either spatial UI or virtual objects opposed to completed scenes that combinate with the physical environment entirely. Museums, art galleries and cultural heritage spaces have a high potentiality to project an entire MR scene compromising of virtual locations, storytelling, characters, objects and UI. This paper addresses a gap in current holographical research, by introducing the ambient information visualisation concept to give MR developers the opportunity to create greater interactive and visually impactful scenes and 3D visualisations.

This paper further contributes to the ongoing studies in ambient information guidance and retrieval for museums using MR technologies. The test procedure for this study required visitors to the Egyptian department in the Manchester Museum to experience an MR application by observing a holographic historical scene 'The Battle' rendered in a real-time augmented environment. This approach provides an accessible and captivating cinematic storytelling experience of ancient Egypt. Additionally, this research measures social acceptance by adopting the Technology Acceptance Model (TAM) [18]. The objective of this approach is to provide grounding for visitor reaction towards MR technologies concerning; personal innovativeness, enjoyment, usefulness, ease of use and willingness of future use.

\section{Mixed Reality and Visualisation methods}

\subsection{Ambient Information Visualisation}

Information visualisation methods can increase human cognition, and convey real-time information to individuals in public places [4]. Card et al. define this process as, "the use of computer-supported, interactive, visual representations of abstract data to amplify cognition" [19]. Ambient visualisations project displays on the surrounding environment and within the peripheral view of the user, therefore exceeding the visual limitations inherent in tv screens, mobile phones and desktop computers [4]. However, ambient information in MR technologies can traverse the line between the virtual peripheral scope and the centre of the user's attention [20]. Therefore, ambient display modules are becoming more frequently employed in public spaces as a virtual overlay on the physical environment[4].

Museum exhibits and displays provide an entertaining visitor experience. However, the ambient information visualisation has the potential to immerse the museum visitor in a new and highly captivating informational experience. Furthermore, this approach permits visitors to visually engage with virtual artefacts in a less restricted environment that the physical space [21]. A similar study utilising large-scale pinwheels in a museum installation further supports the ambient information visualisation approach as results advocated high levels of positive user experience during the performance[22]. The ambient system has the potential to reify our understanding of the typical museum experience by reshaping its displays and exhibits[23]. 


\subsection{Interactive Storytelling}

Museums have implemented computer-based interactive applications for many years. However, due to the widespread utilisation of screen-based applications in modern society, this platform has become less impactful in the museum environment [24]. Screen-based interactivity is limited to touch-enabled buttons and triggers. However, hands-free gesture control instigates a more naturalistic and unprohibited mode of human-computer interaction, particularly while telling stories. Increasing the level of user interactivity and freedom of movement can enhance the museum experience as opposed to immobile computational screenbased technologies [24]. The museum environment allows visitors to explore and gain knowledge and generate their ideas and concepts through exploration of exhibits and play [12]. Museums can encapture people's imagination and promote inquiry skill building and follow-up activities conducted at home or in school. However, museums require additional mediation techniques to enhance assessability and engagement to promote further learning through storytelling and historical narrative.

Storytelling is profoundly rooted in human learning and provides an organised structure for new experiences and knowledge [25]. Information is understood and interpreted more effectively if organised into the form of a story. Social activities such as theatrical plays and dramatised performances can be used to share cultural experiences through linear narrative progression [26]. Social interaction and collaboration in storytelling can create 'social synergy' and have a more significant impact on visitors than individual experiences [27]. Typically non-linear storytelling approaches are implemented in museums [24], some virtual museum applications have also implemented this approach [27] other applications considered storytelling as non-formal educational performance [28] [29]. Interactive digital storytelling permits web users to explore virtual museums to increase information accessibility [30]. Many authors incorporated audio guiding storytelling with virtual exhibitions [31]. Another form of interactive storytelling immerses visitors in real-time virtual environments with engaging visual representations [32]. A further study exploited a real avatar in a virtual cultural heritage context for storytelling purposes [33]. Recently, interactive storytelling became a broader concept to involve different disciplines, so the comprehensive guidelines for designing multimedia interactive storytelling techniques was introduced [34].

\subsection{Visualisation Techniques}

Since the advent of museums, information visualisation has taken many forms to communicate historical documentation to visitors. Traditionally museums used text labels to display information; this progressed to wall mounted displays, printed posters and electronic displays. Paper-based notifications and wall posters were also used to instruct visitor navigation around museums [35]. Many modern museums have embraced digital interactive technologies and static displays alongside traditional informative visualisation methods. The 'PEACH' project is an example of an interactive museum application that projects personalised TV-quality presentations to engage a younger generation of museum-goers [36, 37]. Comparatively, Raptis, Tselios [38] suggests that interactive devices such as smart tables are more suited for museum environments than projections. Similar studies indicate that smart tabletops are of more significant benefit in museum settings as they permit better social interplay $[39,40]$. Digital tabletop games are often used to engage visitors through interactive play which can enhance learning through image-based historical content [41]. Information visualisation and artificial intelligence systems can combine to produce virtual human guides. These virtual humanoids can vocally interact with visitors using natural human language processing [42]. In recent years the application of Augmented Reality (AR) and Virtual Reality (VR) visualisation tools have significantly increased in museums worldwide [43] [44]. Although AR and VR are considered cutting-edge technologies, MR is more immersive as it enables the simultaneous overlap of virtual and real environments. The following section examines immersive storytelling in MR systems using head-mounted displays (HMD).

\subsection{Mixed Reality}

Over the past two decades, the Reality-Virtuality Continuum [45] was coined to define the digital visualisation methods incorporated within mixed reality, virtual reality and augmented reality. However, purely virtual methods progressed to include both virtual and physical environments simultaneously. Bray [1] exemplifies this procedure in Fig 1. Technological advancements in sensor tracking and sensitivity allow users to explore physical environments through virtual interfacing using spatial mapping techniques. 


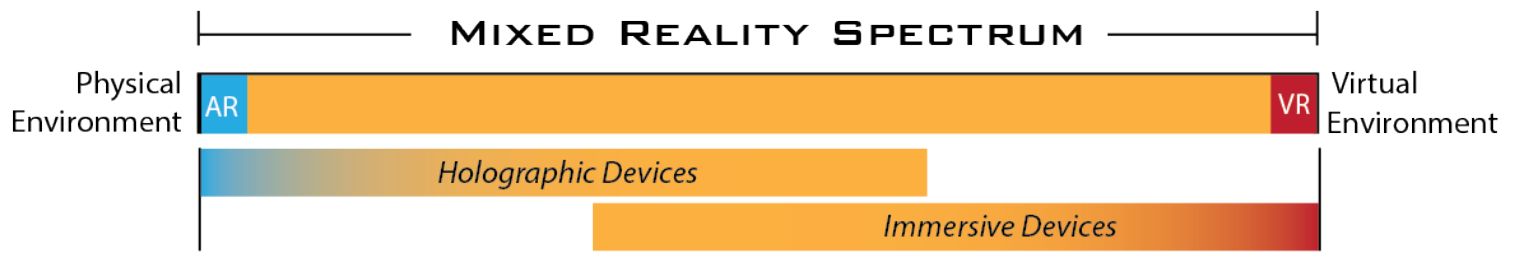

Fig 1. Mixed Reality concept by [1] and allocation of Holographic and immersive devices

There are numerous examples of holographic HMD devices such as the Microsoft HoloLens [46], Magic Leap [47], Meta 2 [48]. However, public acceptance of digital visualisation headsets that display Augmented/mixed reality in museums is of significant concern for museology researchers and practitioners since 1998. For instance, Rekimoto [49] adapted the 'Sony GlassTron HMD' to scan fiducial markers in order to project an augmented reality environment. The 'ARCHEOGUIDE' project developed for the museology field equipped the user with a mobile computing unit in a backpack utility connected to a see-through Headset and earpiece [50]. To effectively validate the practicalities of wearable devices in museum environments, Damala \& Marchal [49] measured the ergonomic capability of AR devices by mounting a tiny computer screen on an HMD to view the environment around them.

Furthermore, a project called 'ARtSENSE' used AR glasses accompanied by various types of sensors such as biosensors and acoustical sensors [51]. MR headsets such as the Microsoft HoloLens was utilised recently in projects such as 'HoloMuse' that engage users with archaeological artefacts through gesture-based interactions [16]. HoloLens were also contributed to restoration in Art galleries by adding a virtual extension of the actual antiques in [52]. Another holographical project conducted an immersive interactive experience to explore the potential of MR in museums [53]. Recently, HoloMuseum emerged, and it has more common concepts and functionalities to this research project as it provides a management tool to explore the virtual extension of the exhibited antiques [15]. Furthermore, MR HMDs for engaging cultural visitors with gaming activities were developed [54].

Visual storytelling in MR is an integrated multimodal communication technique [55]. Another study involved mixed reality with interactive storytelling to explore the user experience and their responses [56]. A similar study named 'SEA CREATURES' used a see-through video HMD as a visualisation tool for storytelling [57]. Recently, a study introduced a framework to provide a personalised and engaging multimedia storytelling tool for museum visitors using MR [58] However, despite previous studies in MR, there is a distinct lack of research in cinematic storytelling by spatial visualisation HMD utilities such the Microsoft HoloLens with the sense of presence. This study seeks to engage visitors in interactive and immersive storytelling by enhancing the traditional museum experience using a non-formal animation based educational approach.

\section{System Design}

In this section, a system for museum information visualisation storytelling is discussed to help display visitor information using visual holograms. This approach explores mixed reality technology in a guidance systems approach 'AIVC' enabling visitors to interact with information in gradual levels.

\subsection{The Ambient Information Visualisation Concept (AIVC)}

The ambient information visualisation system provides a continuous cycle of interactive data through a sphere of visuals around the operator. The design places the spectator at the centre of a multilevel globe populated with physical and virtual objects used to communicate ideas and guide visitors are the museum. The AVIC as potential application in the Microsoft HoloLens [46], Meta Glasses [48], Magic leap [47] and is designed to effectively communicate information with the user through three layers which are separated spatially. In order to avoid operator confusion, the number of interactions and visualisations depends on the need and the depth of a particular scene as depicted in figure 2. The virtual artefacts situate in proximity to the user for accurate hand gesture registration. Performing a click/air tap by Microsoft HoloLens requires three stages: head movement as a directional pointer, eye tracking as a virtual mouse, and hand gesture control as a trigger.

Tracking the operators head positing directs the gaze point controller towards virtual button in the UI design layout enabling users to perform hand gestures to trigger functions. The virtual guide layer projects 
an animated narrator who delivers information regarding the current scene. The outer virtual layer projects background animated characters with virtual objects to enhance the scene environment. The final layer is a composition of both virtual and physical environments into a single unified spectrum. The objective of the AIVC is to widen the communication abilities of museum visitors to engage in a higher mode of interactive entertainment.

The following section analyses the composition and application of the AR scene 'The Battle'.

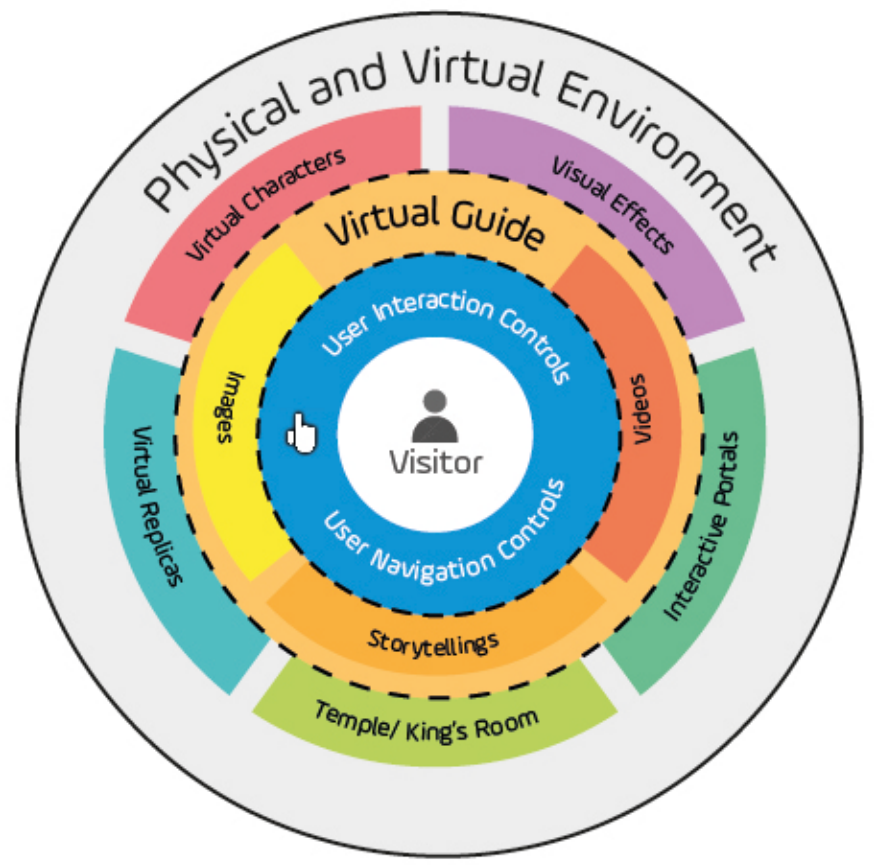

Fig 2. Ambient Information Visualisation Concept (AIVC) for the Battle system.

\section{2 'The Battle' System: Background}

The primary aim of 'The Battle' environment is to offer an informative and entertaining MR experience to museum visitors while analysing the ambient information visualisation concept. The system utilises a storytelling visualisation technique within a museum room of the same context. The objective of this approach is to create a lasting visitor experience and fulfil museum visitor needs that Packer and Ballantyne [59] evaluated. The research study examined: learning and discovery, passive enjoyment, restoration, social interaction and self-fulfilment. The proposed system considers Packer and Ballantyne [59] outcomes by creating functions within the system design to reflect the visitor experience requirements. The Battle system is an evaluation approach to introduce the ambient visualisation storytelling tool in a museum environment to inform visitors and engage them during their tour.

\subsection{System Architecture}

The system functions within a physical environment utilising the ground, walls and spaces between objects and developed according to the AIVC in figure 2, as the user faces the user interface controls which can provide the control of starting /stopping/ pausing the stories narration by hand interactions. This layer also gives the user the ability to navigate between the other narratives' scenes. The following layer starts with the virtual narrator, and it is an avatar of King Tutankhamun and who tells the stories about himself and his dynasty and what he achieved during his period. During the storytelling, he points to complementary images and video of the tomb inscriptions that represent his gods, family and enemies. The third layer starts after 4 minutes of his demonstration when he starts to tell stories about his wars with enemies as the viewer can look around and see the temple of the king projected around accompanied with virtual supplementary characters such as guards and maids and with some visual effects. Then, the battle scene starts as it comprises of animatic characters, artefacts, sound effects and epic background music to simulate and dramatise in 30 seconds of the visceral experience of war.

Fig 3, depicts the system pipeline comprised of seven phases. The first phase displays two-dimensional graphical elements that assemble the UI assets of the navigation panel created in Adobe Photoshop and Adobe Illustrator. 


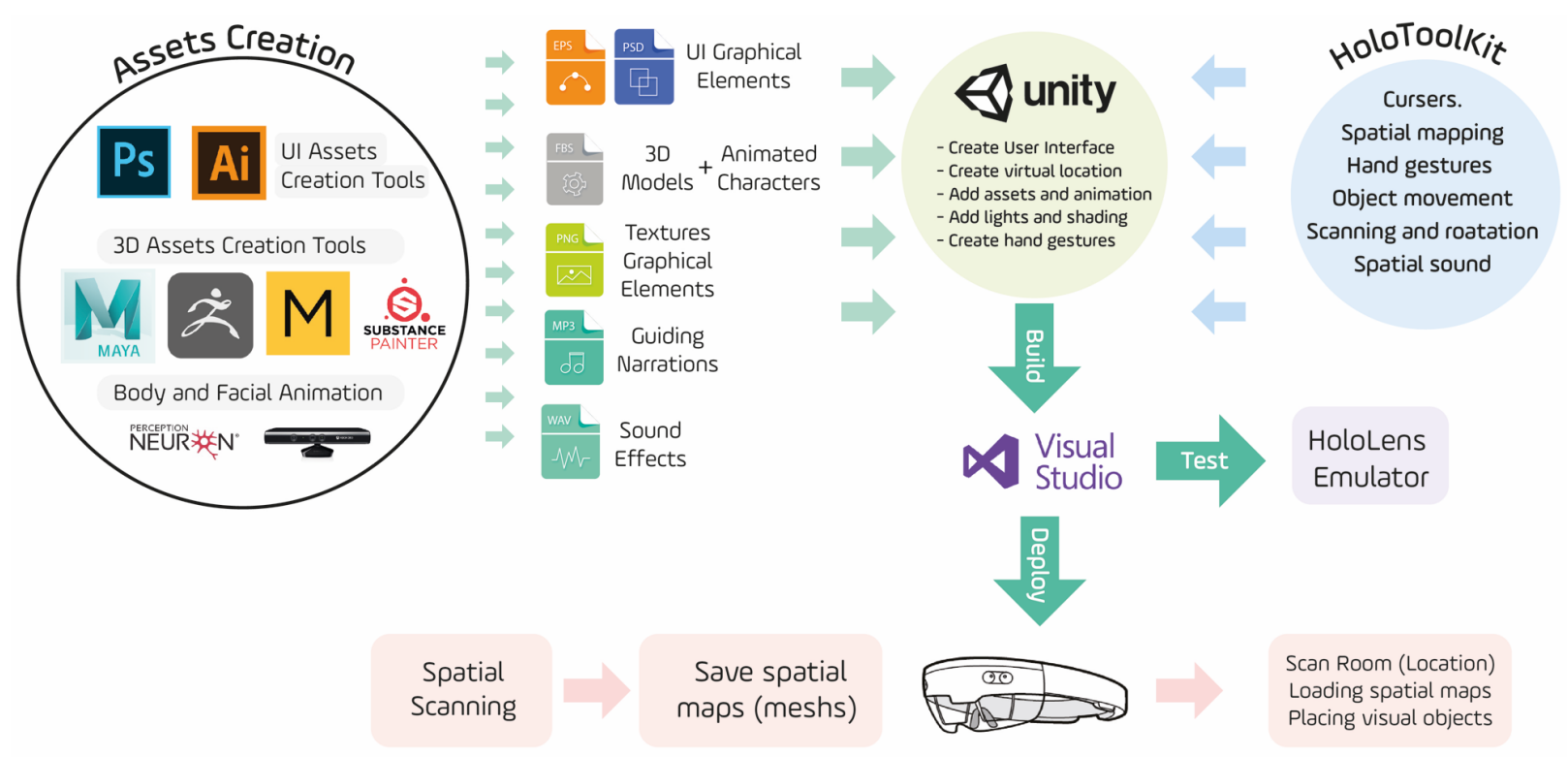

Fig 3. System Structure

The 3D elements in the battle scene reference images and characters depicting Egyptian kings and soldiers fighting their enemies, Fig 4. 2D line drawing plans are converted to 3D models using ZBrush and Autodesk Maya and Marvellous designer. Substance Painter creates texture effects to create realistic skin and material effects. The king, minister, his soldiers and enemies are animated in Autodesk Maya and a motion capture suit 'Perception Neuron' translates natural bodily movement. A Microsoft Kinect sensor with a face tracking library tracked human facial movements to create accurate facial expressions of the animated characters. After the 3D characters created, they were sent to academic and professional historians and archaeologists to validate the visual appearance and all suggested modifications considered. Moreover, the narrative content of King Tutankhamun's dynasty is formed using historical references [60] [61] [62]. The recorded narratives were also sent to the same group of experts to validate them before embedding them into the system.

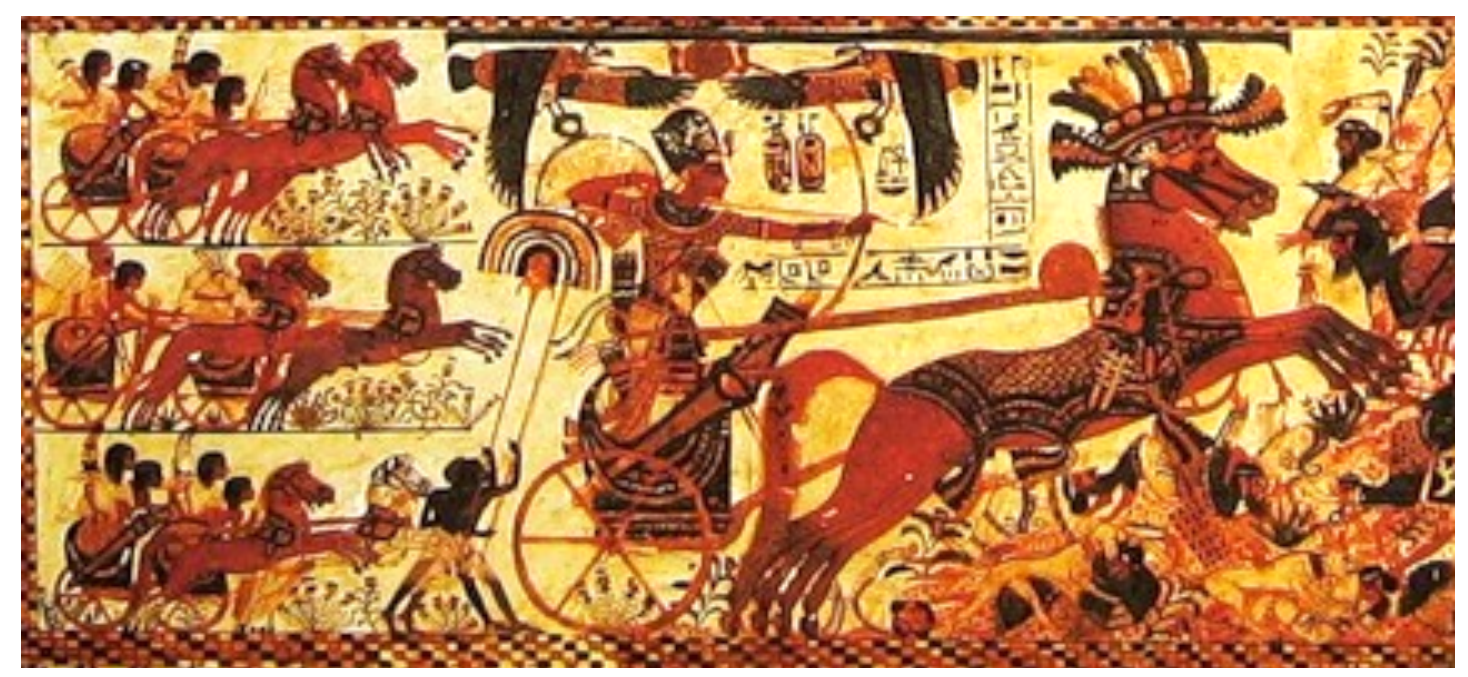

Fig 4. Image from [63] represents the reference of "The Battle."

The second stage composites the application in Unity, by importing all assets and scripts including audio files of sound effects and narration into the HoloToolKit. The functionality of cursers, spatial mapping, hand gestures, object movement and the spatial sound configures upon opening the application. The UI is transfixed close to the camera in the virtual scene, setting the positions of the 3D assets, characters, the location of the battle and the other props into place, Fig 5. It is essential to allocate space for the user at the centre of the virtual environment when considering the ambient information visualisation concept. Adding lighting effects and shadowing techniques help blend the virtual and physical realms. Controls for hand gesture interactions in the UI are applied using the scene configuration window in Unity. 
The third stage renders and builds the application in Unity for export in Microsoft Visual Studio 2017. The application is assessed using the HoloLens Emulator plugin to inspect the application's functionalities virtually without deploying it into the headset. This approach saves time and permits bugs fixing to test system functionality before final deployment in the HoloLens HMD.

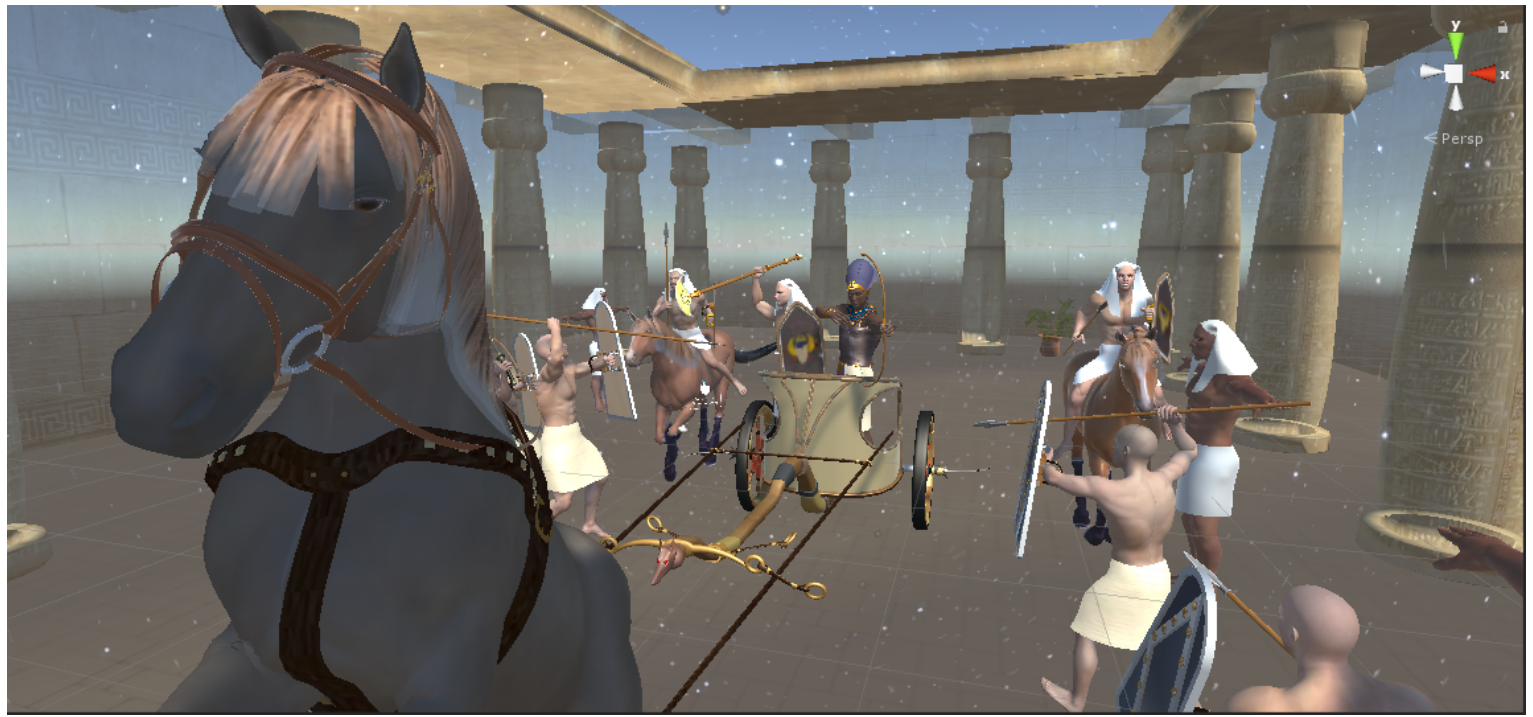

Fig 5. 'The Battle' development in Unity3D

The fourth stage transfigures virtual spatial maps for the physical environment using the Microsoft HoloLens scanning capability to process the real environment. The HoloLens saves this data in a library of the HMD as a set of environmental meshes.

These spatial meshes represent the parameters of a physical room within the virtual scene and are the base for the virtual overlay. When the user opens the HoloLens application, it automatically scans the room and orientates the system with existing spatial maps in the library until it recognises the real environment.

'The Battle' scene features long-lasting virtual object positions; this allows holograms to build in the same location quickly. The system features a 'World anchor' tool to recognise the visual cues of areas within the physical environment to augment the 3D environment without adjusting the spatial settings. The optimum environment for the hologram system has low lighting levels and it is advised not to be exposed to the sunlight as it penetrates the presented holograms and lower their opacity.

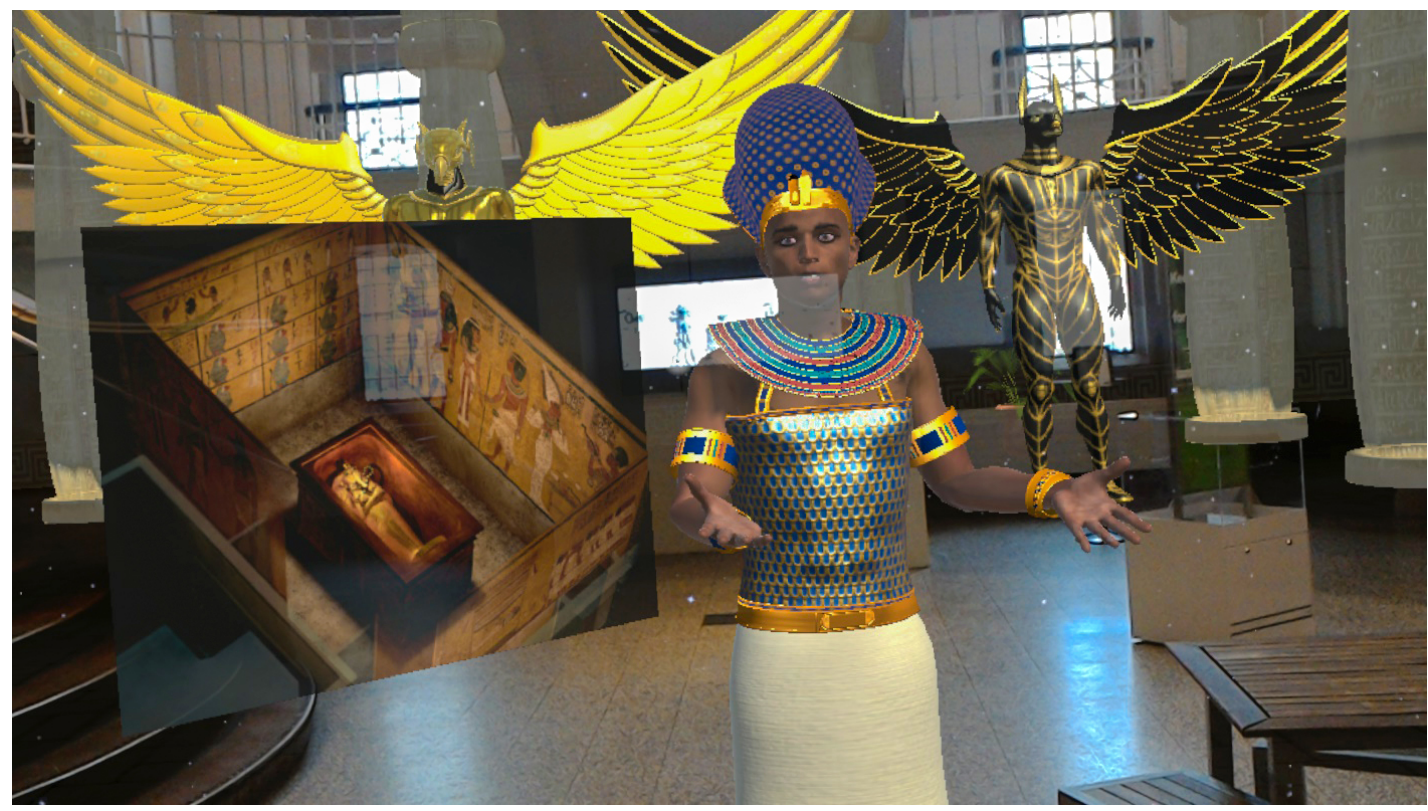

Fig 6. The virtual narrator of 'The Battle' scene. 
One of the interesting features of the system is the ability to share the visuals and receive the interactions from more than one user in the real-time. So, if multiple users wear the headset at the same time in the same room, they can simultaneously share the experience and have social interactions while the storytelling visuals display.

\subsection{Hardware}

The 'Microsoft HoloLens' AR HMD is a portable, wearable computer system and a holographical display device. The HoloLens, Fig 7 implements the Intel 32-bit (1GHz) processor, 2 GB RAM, Accelerometer, gyroscope and magnetometer, and battery for 2-3 hours of active use and Windows 10 [46].

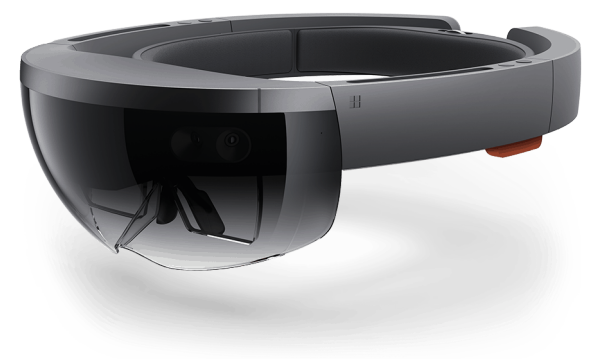

Fig 7. Microsoft HoloLens -Source: [46]

\subsection{System Implementation}

As part of the system validation procedure, the Manchester museum's experts and curators who work in the Egyptian department examined the visual and spatially ability of application during the battle scene. Study participants invites were sent through social media outlets and to selected university members with interests in museums. A random sample of museum visitors received invites to experience the system during their tour in the Egyptian department, Fig 8.

\subsection{Participants}

Hardware limitations of utilising a single device reduced the testing time at the museum; the study involved 47 participants from the daily visitors of the museum including participants who accepted the invitation from social media. A comparable study in a museum user experience utilised a sample range of 50 participants, further supporting the pilot study sample range [64]. An equality sampling methodology divided the experiment into (42.6\%) male and (57.4\%) female to reduce gender bias.

All participants received a demonstration including a short tutorial on controls, safety and usage time.

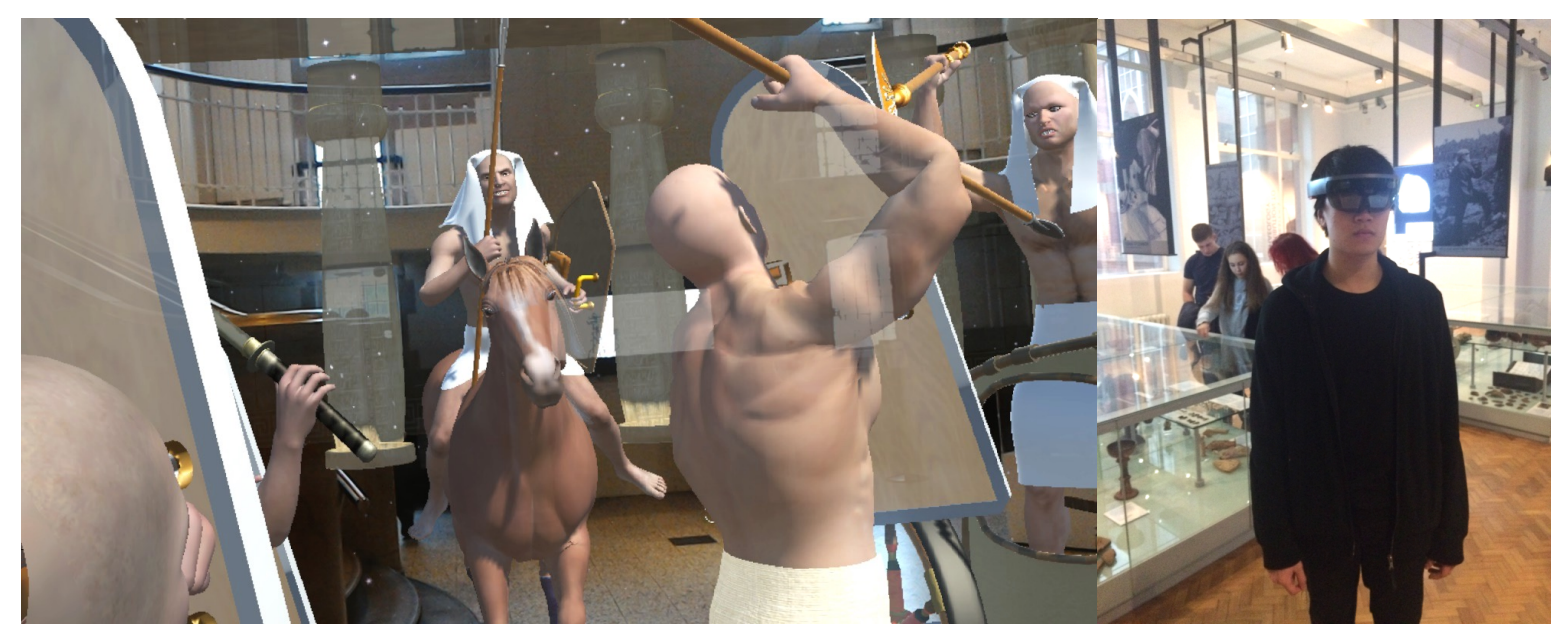

Fig 8. 'The Battle' as seen from the headset (left) - museum participant (right) 


\section{Research Model}

\subsection{Technology Acceptance Model (TAM)}

The TAM framework measures the user's acceptance of new technologies [65]. Data extrapolated from this model helps explain how users perceive and adapt to new technologies[66]. The technology acceptance model is fundamental for any new system development and validation [67], [68]. TAM has application in Mixed Reality research. However, AR technology is still emerging commercially and in academia [69].

Furthermore, research into TAM applications in AR primarily examines cultural heritage environments utilising the Reality-Virtuality Continuum of Milligram [45] [70] [71] [64]. However, although the development of holographic devices has grown, little research exists which examines the public acceptance of this new technology [72] [73] [74]. According to the TAM framework, the acceptance of a system depends on its application and intention to use it. TAM analysis the user's behaviour calculated on the theory of reasoned action created by Fishbein and Ajzen [75]. The intention to use phase explores the attitude of the user towards the application, usefulness and accessibility [68]. The perceived usefulness and the perceived ease of use together are determined by external variables. These variables define the user characteristics, nature of the system, the way the system used and the location setting. The external stimulus may consider personal innovativeness [76] that directly influences the usefulness and the ease of use of a system.

These factors are essential parts of the TAM model developed by Davis [77], Fig 9.

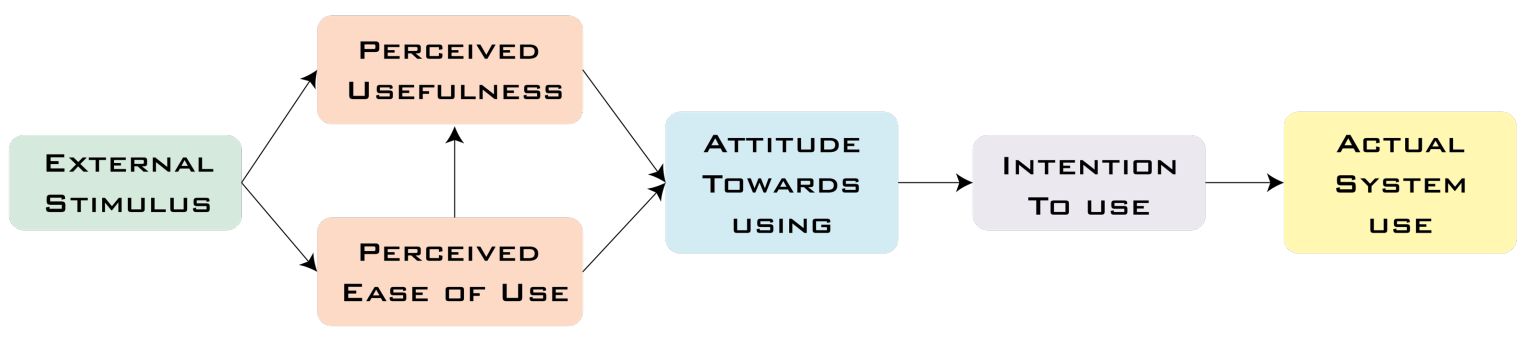

Fig 9. Technology Acceptance model and developed from Davis [77]

\subsection{TAM Constructs of 'The Battle'}

This research implements the basic constructs of the TAM model by analysing the users; perceived ease of use perceived usefulness and the willingness of future use. This simplified approach underpins 'The Battle' application design to examine the user's acceptability of the system for future use.

The Personal Innovativeness (PI) model examines the willingness of the user to experience new technology [78] and the influence of individual traits on the motivational stimulus [79]. The PI approach underpins a theoretical treatise named the 'Innovation Diffusion Theory' which examines the relationship between the personality of the user and new technology [80]. The innovation diffusion theory argues that users with high levels of internal stimulation, tend to have a more positive attitude towards using technology daily. Similar results of a study measuring the online shopping behaviour of the avid traveller support the innovation diffusion theory [71]. Several TAM studies that investigated mobile museum guides supported PI in their frameworks [81] [70] [82]. Therefore, an adaptation of the user experience model for implementation in mixed reality applications for museum environments may induce a higher mode of user acceptability.

Moreover, the potential application of the system in a live museum environment explores [83], personal innovation [84] and usefulness [78]. Studies of mobile applications [85] [81] emphasised on the influence of PI on the perceived usefulness and ease of use. According to Davis, perceived enjoyment (ENJ) considers "the extent to which the activity of using the computer is perceived to be enjoyable in its own right, apart from any anticipated performance consequences" [86]. The ENJ framework was used to determine the acceptance of the technology in information systems, [87] [88] [89] by implementing the Davis TAM model. Similar studies prove that ease of use and usefulness influenced the amount of user engagement and entertainment [90] [91] [92].

The perceived ease of use (EOU) model considers, "the degree of effort to use a system" [66]. This approach examines the behavioural traits that affect the user's intention of accepting technology. The ease of use construct is applied in the current research model as it measures the user satisfaction level when utilising the mixed reality system. In some researches, ease of use influenced the intention to use construct in information technology discipline [93]. The perceived usefulness (USF) analyses "the degree to which a 
person believes that using a particular system would enhance his or her job performance" [66] application in the new research model will measure the functionality of the system [94]. The objectives of the UX approach is to evaluate the intention to use, enjoyment level, ease of use, usefulness and future use as intrinsic constructs for 'The Battle' scene, which adopted the ambient information visualisation concept.

UX approaches applied to the new research model, Fig 10:

H1: Personal innovativeness (PI) will positively affect the perceived ease of use (EOU).

H2: Personal innovativeness (PI) will positively affect the perceived enjoyment (ENJ).

H3: Personal innovativeness (PI) will positively affect the perceived usefulness (USF).

H4: Perceived enjoyment (ENJ) will positively affect the perceived ease of use (EOU).

H5: Perceived enjoyment (ENJ) will positively affect the perceived usefulness (USF).

H6: Perceived ease of use (EOU) will positively affect the willingness of future use (WFU).

H7: Perceived enjoyment (ENJ) will positively affect the willingness of future use (WFU).

H8: Perceived usefulness (USF) will positively affect the willingness of future use (WFU).

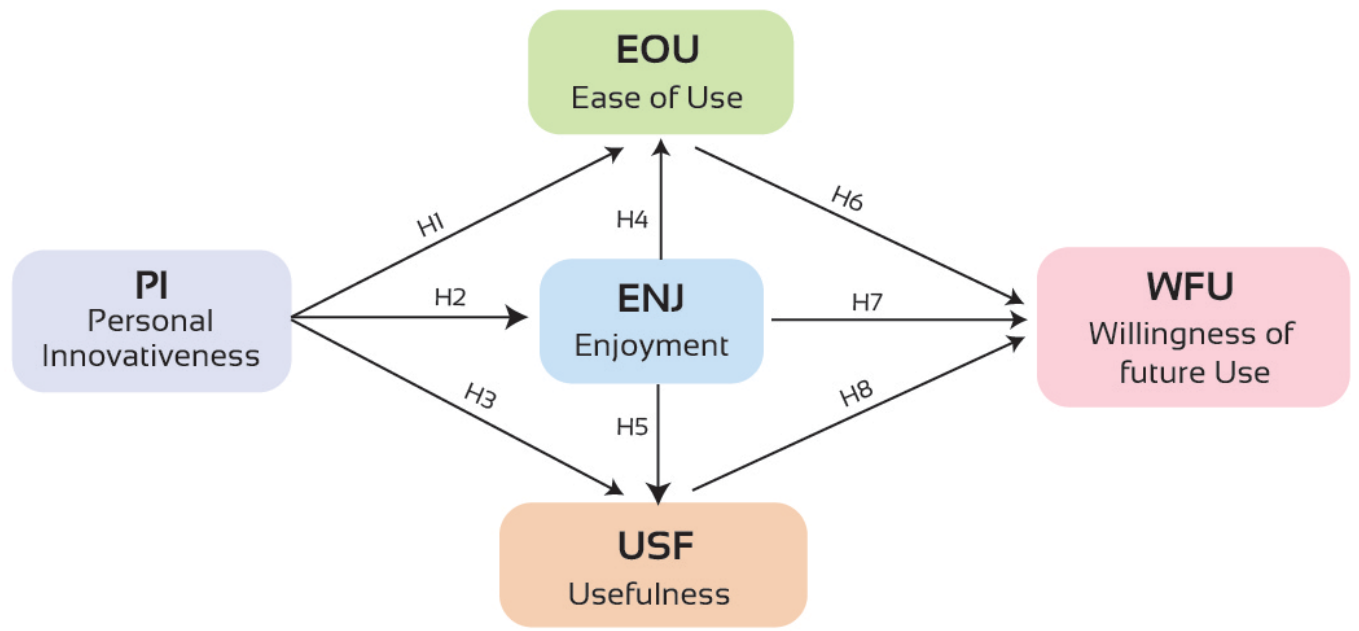

Fig 10. Research Model based on Technology Acceptance Model

\subsection{Data Collection}

'The Battle' was piloted using a population sample of seven academic researchers to test the usability of the system. Based on these outcomes amendments were taken into consideration to prepare the system for usage in the museum. The technology acceptance model was applied in this research study to measure taskperformance. A questionnaire consisting of 19 questions to assess and measure the visitor's behaviour towards the AIVC prototype 'The Battle' The questions consider the UX models: personal innovativeness (PI), enjoyment (ENJ), ease of use (EOU), usefulness (USF) and willingness of future use (WFU). The measurement of these five constructs are calculated using a Likert scale as follows: strongly disagree $=1$, disagree $=2$, neutral $=3$, agree $=4$, strongly agree .

\section{Findings}

\subsection{Reliability Test}

To test system reliability Cronbach's alpha model was used across the five constructs as presented in table 1. Personal innovativeness registered as a reliable construct in some similar studies such as [79] with 0.82 and [95] with 0.85 this study demonstrated a reliability factor of 0.84 . Enjoyment level as stated in the studies [67] at 0.87 and [87] as 0.88 concluded in this study at 0.96 . Ease of use reported in [67] as 0.77 and in [96] as 0.67 , achieved 0.89 in this study. Usefulness and willingness of future use respectively resulted in values 0.83 and 0.92 . 


\subsection{Factor Analysis}

Analysis of the five factors resulted in $80 \%$ of the total variance. The factor loading indicated 0.6 or above, and all results below 0.6 where disregarded. Hence, the constructs became unidimensional with discrete factors; operationalised into a single factor.

Table 1. System Reliability and Factor validity: Varimax rotation and Kaiser normal was the principal axis factoring, $\mathrm{N}=47$

\begin{tabular}{|c|c|c|c|c|c|c|c|}
\hline Constructs & Items & $\begin{array}{c}\text { Factor } \\
1\end{array}$ & $\begin{array}{l}\text { Factor } \\
2\end{array}$ & $\begin{array}{c}\text { Factor } \\
3\end{array}$ & $\begin{array}{c}\text { Factor } \\
4\end{array}$ & $\begin{array}{c}\text { Factor } \\
5\end{array}$ & $\begin{array}{c}\text { Cronbach's } \\
\text { Alpha }\end{array}$ \\
\hline \multirow{4}{*}{$\begin{array}{c}\text { Personal } \\
\text { Innovativeness } \\
\text { (PI) }\end{array}$} & PI1 & & & & 0.794 & & \multirow[t]{4}{*}{0.841} \\
\hline & PI2 & & & & 0.687 & & \\
\hline & PI3 & & & & 0.703 & & \\
\hline & PI4 & & & & 0.687 & & \\
\hline \multirow{5}{*}{$\begin{array}{l}\text { Enjoyment } \\
\text { (ENJ) }\end{array}$} & EJ1 & 0.744 & & & & & \multirow[t]{5}{*}{0.962} \\
\hline & EJ2 & 0.789 & & & & & \\
\hline & EJ3 & 0.875 & & & & & \\
\hline & EJ4 & 0.862 & & & & & \\
\hline & EJ5 & 0.790 & & & & & \\
\hline \multirow{4}{*}{$\begin{array}{l}\text { Ease of use } \\
\quad \text { (EOU) }\end{array}$} & EOU1 & & 0.810 & & & & \multirow[t]{4}{*}{0.898} \\
\hline & EOU2 & & 0.803 & & & & \\
\hline & EOU3 & & 0.736 & & & & \\
\hline & EOU4 & & 0.845 & & & & \\
\hline \multirow{4}{*}{$\begin{array}{l}\text { Usefulness } \\
\text { (USF) }\end{array}$} & USF1 & & & & & 0.646 & \multirow[t]{4}{*}{0.833} \\
\hline & USF2 & & & & & 0.861 & \\
\hline & USF3 & & & & & 0.652 & \\
\hline & USF4 & & & & & 0.834 & \\
\hline \multirow{4}{*}{$\begin{array}{c}\text { The willingness } \\
\text { of Future Usage } \\
\text { (WFU) }\end{array}$} & WFU1 & & & 0.760 & & & \multirow[t]{4}{*}{0.920} \\
\hline & WFU2 & & & 0.734 & & & \\
\hline & WFU3 & & & 0.963 & & & \\
\hline & WFU4 & & & 0.963 & & & \\
\hline $\begin{array}{c}\% \text { of variance } \\
\text { explained }\end{array}$ & & 20.41 & 16.09 & 15.92 & 14.75 & 12.81 & \\
\hline $\begin{array}{l}\text { Cumulative } \\
\text { percentage }\end{array}$ & & 20.41 & 36.51 & 52.44 & 67.19 & 80.00 & \\
\hline
\end{tabular}

\subsection{Demographics of the visitors}

The study included 47 visitors of Manchester museum who either accepted the online invitation or volunteered to participate in the study during their visit to the museum as shown in table 2. Forty-two per cent of participants were male $(n=20)$ and fifty-seven per cent of the participant were female $(n=27)$. The age range of participants included, (46.8\%) 18 and 25 years old, (48.9\%) 26-40 years old, and a single participant was between 41 to 60 years old. Nineteen (40.4\%) participants were in college or undergraduate students, twenty-two (46.8\%) are university graduates, and six (12.7\%) are either master or PhD holders. 
Table 2. Demographic profile of participants ( $=47 ; 2$ Point scale)

\begin{tabular}{|c|c|c|c|c|}
\hline Measure & Yes & No & Mean & Std. Dev. \\
\hline Aware of AR/MR & $48.9 \%$ & $51.0 \%$ & 1.49 & .505 \\
\hline Wear HMD & $17.0 \%$ & $82.9 \%$ & 1.17 & .380 \\
\hline Heard of AR/MR Applications & $36.1 \%$ & $63.8 \%$ & 1.36 & .486 \\
\hline Used AR applications & $29.7 \%$ & $70.2 \%$ & 1.30 & .462 \\
\hline Experienced AR in museums & $0.0 \%$ & $100 \%$ & 1.00 & .000 \\
\hline
\end{tabular}

Over half the sample the recognised AR/VR/MR technologies and $17 \%$ of them had experience wearing AR/VR/MR devices such as Oculus Rift, Google Cardboard and Samsung Gear VR. Around the third of the participants used AR/VR/MR applications, while none had experienced AR in museums.

\subsection{Intention to experience a new system (Personal Innovativeness - PI)}

Results of 'The Battle' experience highlight the level of intention to experience the system, as $68 \%$ strongly agree on being motivated to try new technology. However, $53 \%$ strongly agreed that they wanted to experience new technology. Mean values were generally high, as the lowest was 4.51 for item PI4 and the highest was for the item PI3 at 4.66 which indicates a high level of intention to involve in new experiences in museums (see appendix).

\subsection{Enjoyment (ENJ)}

Results of the enjoyment factor examination showed that ENJ4 and ENJ5 items were the highest ratings. As $19.1 \%$ strongly agreed and $61.7 \%$ agreed on being immersed, and they felt as they were in the battle arena. As suggest participants strongly agreed that they enjoyed during the storytelling and for being in the middle of the battle the scene. The lowest item was ENJ2 as $12.8 \%$ of participants strongly agreed on being excited during the scene, and 61.7\% agreed. Overall, the highest mean value in ENJ5 indicated that a standard deviation is between 0.522-0.547 (see appendix).

\subsection{Ease of Use (EOU)}

The rating of the ease of use 'The Battle' system with AIVC outcome with $68 \%$ of participants strongly agreed, and $31.9 \%$ agreed on the ability to use the system unaided in item EOU4 as the highest. While $57.4 \%$ strongly agreed and $42.4 \%$ agreed on the ability to explore the environment while watching the battle. In item EOU1 as the lowest. The highest mean was 4.68 in item EOU4, and the lowest mean was 4.57 in item EOU1 which are considered high values. The range of standard deviation is between 0.471-0.500.

\subsection{Usefulness (USF)}

The results of the perceived usefulness of the system showed that $63.8 \%$ of the participants strongly believed of the ability of the technology to visualise the historical stories in the item USF3 as the highest. While $55.3 \%$ of participants strongly agreed on the usefulness of the technology towards enriching the museum experience in item USF2 as the lowest. The highest mean is item USF3 at 4.62, and the lowest mean was 4.51 in items USF2 and USF4. The range of standard deviation is between 0.534-0.585.

\subsection{Willingness of Future Use (WFU)}

The results of the willingness to use the system in future visits to the museum revealed that $31.9 \%$ of participants strongly agreed on the intention to use similar applications like 'The Battle' in future visits in item WFU3 as the highest. Moreover, many stated that they would pay to rent it. However, $23.4 \%$ strongly agreed on using the system once it is available in the museum in item WFU1 as the lowest. The highest mean was 4.87 in items WFU3, and WFU4 and the lowest was 4.79 for item WFU1, which make the range quite high. The range of standard deviation is between 0.337-0.414.

Table 3 presents an analysis of the five constructs of the study. All responses from participants were positive towards the investigated constructs. The highest construct has an overall mean of 4.83 for the willingness of future use. Enjoyment ratio indicated a value of 3.92. The lowest outcomes of enjoyment have an overall mean of 3.92 out of 5.0. All aspects indicated a high potential of acceptance from visitors towards the application and technology. 
Table 3. The willingness of future use variable

\begin{tabular}{|c|c|c|}
\hline Variables & Mean & Std. Dev. \\
\hline Personal Innovativeness (PI) & 4.57 & 0.442 \\
\hline Enjoyment (ENJ) & 3.92 & 0.593 \\
\hline Ease of use (EOU) & 4.54 & 0.459 \\
\hline Usefulness (USF) & 4.63 & 0.529 \\
\hline The willingness of future use (WFU) & 4.83 & 0.334 \\
\hline
\end{tabular}

\subsection{Regression Analysis}

In order to verify the outcomes, cross-analysis of the relationships between pairs of results indicated. Correlation coefficient $p$ was less than 0.05 for all of the regression values.

Table 4 demonstrates the positive correlations between constructs. Significant relationships between several constructs H1, $\mathrm{H} 2$ and H3, personal innovativeness (PI) and (ENJ) with $(r=0.643, p<0.000)$ explain the change in results as $\left(R^{2}=0.414\right)$ and significant relationship with usefulness (USF) $(r=0.449, p<0.002)$ and explain the change in it with $\left(R^{2}=0.201\right)$. Also, a quite strong correlation between personal innovativeness (PI) and ease of use (EOU) resulted in $(r=0.420, p<0.003)$ but the $R^{2}$ was as high $\left(R^{2}=0.176\right)$. However, clear correlations with ease of use (EOU) and H6 as (EOU) and willingness of future use (WFU) indicates a significant relationship $(r=0.550, p<0.000)$ and $\left(R^{2}=0.303\right)$.

Regarding $\mathrm{H} 4, \mathrm{H} 5$ and $\mathrm{H} 7$, enjoyment (ENJ) have a significant relationship with ease of use (EOU), ( $r=0.570$, $p<0.000)$ and explains the change in results as $\left(R^{2}=0.325\right)$ and usefulness (USF) $(r=0.547, p<0.000)$, with $\left(R^{2}=0.300\right)$. Moreover, the correlation between enjoyment (ENJ) and willingness of future use (WFU) was low $(r=0.327, p<0.010)$ and the regression results were not sufficient $\left(R^{2}=0.107\right)$. H8 presented a low value and dismissed from the data comparison. Figure 9 represents the research model with correlated results verifying the hypothesis.

Table 4. Variables correlations (Note: ${ }^{* * *} \mathrm{p}<0.001{ }^{* *} \mathrm{p}<0.01$ )

\begin{tabular}{|c|c|c|c|c|}
\hline Hypotheses & Relationship & $\boldsymbol{p}$-value $(\boldsymbol{p})$ & Correlation coefficient $(\boldsymbol{r})$ & $\boldsymbol{R}^{\mathbf{2}}$ \\
\hline H2 & PI $\rightarrow$ ENJ & 0.000 & $0.643^{* * *}$ & 0.414 \\
\hline H3 & PI $\rightarrow$ USF & 0.002 & $0.449^{* * *}$ & 0.201 \\
\hline H1 & PI $\rightarrow$ EOU & 0.003 & $0.420^{* * *}$ & 0.176 \\
\hline H4 & ENJ $\rightarrow$ EOU & 0.000 & $0.570^{* * *}$ & 0.325 \\
\hline H5 & ENJ $\rightarrow$ USF & 0.000 & $0.547^{* * *}$ & 0.300 \\
\hline H7 & EOU $\rightarrow$ WFU & 0.000 & $0.550^{* * *}$ & 0.303 \\
\hline H6 & ENJ $\rightarrow$ WFU & 0.010 & $0.327^{* *}$ & 0.107 \\
\hline
\end{tabular}

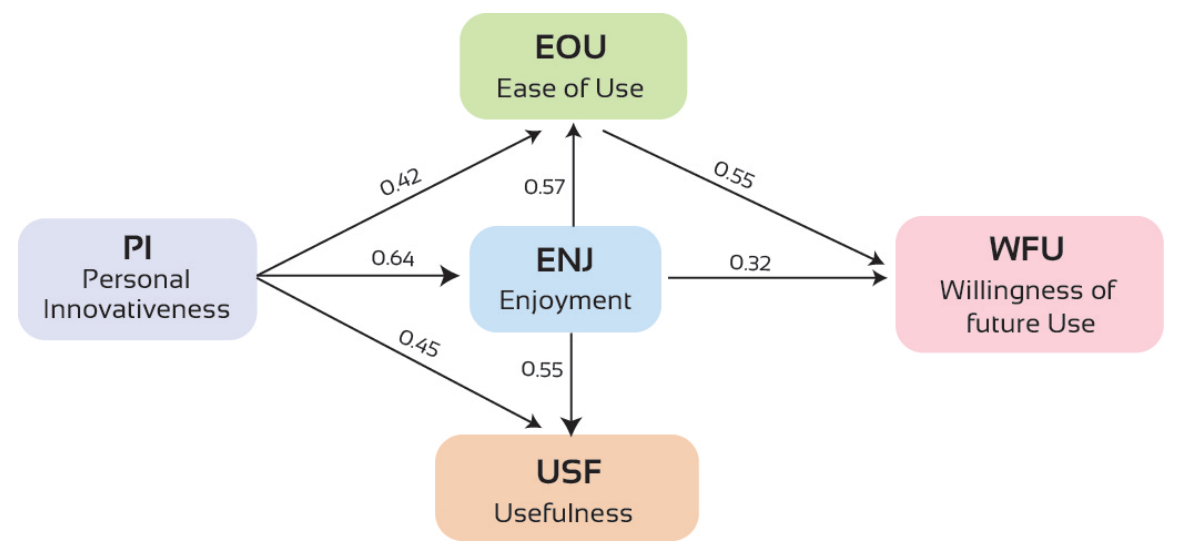

Fig 9. Coefficient correlations for the framework of 'The Battle' with AIVC 


\section{Discussion and Conclusion}

The focus of this study explores public acceptance of mixed reality devices in museums, galleries and cultural heritage places. The Ambient Information Visualisation Concept, AIVC introduces a new method of storytelling that uses the mixed reality application prototype to provide rich visualisations and interactions to enhance the traditional museum experience. A population sample of 47 individuals in Manchester museum indicated that the majority of the participant did not use AR/MR applications, and none had used these technologies in museums. Five UX constructs were explored through 19 questions in a survey to investigate the public acceptance of the ambient information visualisation concept in museums, galleries and cultural heritage spaces. The five constructs founded on the TAM model explored; personal innovativeness (PI), enjoyment (ENJ), usefulness (USF), ease of use (EOU) and willingness of future use (WFU). According to the descriptive analysis, the mean values of the five constructs were highly positive compared with other studies. Personal innovativeness was generally high in this study (mean=4.57) if it compared to [97] as it resulted (mean=3.4). The PI results explain that ages 18 to 40 years are the majority and tend to try new technologies [98]. Also, this can indicate that museums in need of new technology for changing the traditional experience to amuse visitors. Enjoyment (ENJ) was not so much high, but it was moderate (mean=3.92) if it compared to a similar study [71] in the cultural heritage discipline (mean=5.87) when 7.0 is maximum. However, the perceived ease of using (EOU) this system was much higher (mean $=4.54)$ when it compared to [99] as $($ mean $=6.19)$ when maximum in 7.0. The empirical data indicates that the system achieved a better UX for MR users in order to perform the interactions they desire in the first attempt of using HoloLens. The perceived usefulness (USF) produced highly positive results (mean=4.63) when it compared to a similar study [71] that used technology in cultural heritage (mean=5.29) as the maximum is 7.0. The collected data indicates how the new method of storytelling can achieve much usefulness and ability to disseminate information to visitors. The willingness of future use (WFU) resulted in the highest mean among the other constructs (mean=4.83). Comparing the last result with a study [71] that measured this aspect in a similar context (mean=4.3) as 7.0 is maximum. The new data suggesters a high willingness towards using AR/MR technologies combined AIVC in the future.

The results indicate positive correlations between $\mathrm{H} 1$ and $\mathrm{H} 3$, highlighting strong levels of personal traits such as personal innovativeness (PI) towards perceived ease of use (EOU) and perceived usage (USF) resulting in $(p<0.001)$. These findings confirm positive relationships with the prototype models similar to those explored in studies [78] [79]. However, results for (PI) and (EOU) at 0.420 and (PI) and (USF) at 0.449 are stronger than in the previous studies. This outcome shows that museum visitors tend to explore new technologies frequently through personal experimentation, which reflects in their ability to use and adapt to new technologies. Furthermore, the personal motivation of participants to try the application strengthened its potential application in enriching the museum experience. These outcomes can be justified by the sample characteristics which is dominated by participants aged between 14 to 40 and according to Owen, Buhalis [98] who considered these ages are skilful with computers. So, the previous UX in computers aided much to the MR headset system. Outcomes of $\mathrm{H} 2$, suggest a strong correlation between personal innovativeness (PI) and enjoyment (ENJ): $0.643(p<0.001)$, these results align with the outcomes of Hwang [84]. This result reveals that enjoyment factors motivated participants to explore the new technology thus heightening the willingness to use it in future museum visits.

Results of $\mathrm{H} 4$ and H5, show strong correlations between enjoyment (ENJ) and ease of use (EOU) and between (ENJ) and usefulness (USF), showing $0.570,0.547$ and $(p<0.001)$ for both data sets. These outcomes share similar results as previous studies in (ENJ) and (EOU), as indicated in Sun and Zhang [91] at $0.367(p<0.001)$. Moreover, the correlation between enjoyment (ENJ) and usefulness (USF) is stronger than similar studies [91] as they resulted in $0.278(p<0.001)$. These results demonstrate that participants in this study enjoyed using the AR system/application at higher rates the results of previous experiments. Outcomes of H6, show a moderate to a positive correlation between enjoyment (ENJ) and willingness of future use (WFU) at 0.327 while $(p<0.01)$. This result coincides with previous similar studies [90] [91], showing participants enjoyed using the technology, which increased the potential for future use. The ease of use (EOU) implementation indicated a strong correlation with the willingness of future use (WFU) as hypothesised in $\mathrm{H7}$, showing $0.550(p<0.001)$. This result aligns with the results of similar studies [93], with a correlation of $0.33(p<0.001)$, which indicates a weaker correlation compared to the results of this study. Contrary to predictions, H8 showed no correlation between usefulness (USF) and willingness of future use (WFU) as in other similar studies. However, this result is unnecessary for technologies introduced within the context of the museum and cultural heritage environments.

In conclusion, the social norms represented in personal innovativeness to use mixed reality with AIVC in the museum environment influence the enjoyment, ease of use and usefulness. Moreover, perceived 
enjoyment influenced the ease of use. The usefulness of the application and the willingness of participants to adopt the system indicate the potential future use. The intellectual assertations of this study introduced mixed reality accompanied by the ambient information visualisation concept for museums, galleries and cultural heritages spaces. The AIVC concept examined the space of visuals provided by holographic devices by organising the communication and interaction levels to enhance and enrich the museum experience. The practical contribution of this study applied 'The Battle' application based on a storytelling narration of the ancient Egyptian people within the Egyptian department of the Manchester Museum. This paper contributed the system pipeline from initial sketching to the deploying of the system on the headset. The other practical contributions in the research model comprised five constructs of TAM to prove the acceptance of the AIVC technology in museums, galleries and cultural heritage spaces. The system incorporates the cultural heritage presentations guidelines created by [34] as it engaged professionally from different related disciplines either historians in content creation, designers and developers of AR and MR systems and museum curators for system validation. Moreover, the stories were informative, dynamic and interesting enough to enjoy users with the MR holograms. Also, the virtual character 'King Tutankhamun' was employed for emotionally driven communication with visitors to enhance the level of engagement.

Research limitations such as the number of participants involved in the study and the time limit provided by the museum staff affected a potentially greater population same size. The cost of the HoloLens HMD restricted this research to using a one headset per session. Future studies may consider using multiple AR devices to gather data simultaneously to reduce time limitations. The limitations of the multiple devices did not reveal the usefulness of the sharing experience functionality and obstructed the exploration of its impact on the holistic museum experience. The financial investment of the device is considered one of the most significant limitations for museums to embrace these technologies. However, developments in applications and the increasing demand for holographical devices may encourage the industry to produce cost-effective AR HMD.

\section{Acknowledgements}

The British Council Newton-Mosharafa scholarship funded this project. The authors would like to thank Manchester museum staff for their arrangements for the visit and support in conducting the survey and also thank Ziad El Kalha and Ahmed Elamir for their help.

\section{References}

1. Bray, M.Z.B. What is mixed reality? 2018; Available from: https://docs.microsoft.com/en-us/windows/mixedreality/mixed-reality

2. Pousman, Z., J. Stasko, and M. Mateas, Casual information visualization: Depictions of data in everyday life. IEEE transactions on visualization and computer graphics, 2007. 13(6): p. 1145-1152.

3. Wattenberg, M. Baby names, visualization, and social data analysis. in Information Visualization, 2005. INFOVIS 2005. IEEE Symposium on. 2005. IEEE.

4. Skog, T., S. Ljungblad, and L.E. Holmquist. Between aesthetics and utility: designing ambient information visualizations. in Information Visualization, 2003. INFOVIS 2003. IEEE Symposium on. 2003. IEEE.

5. Oppermann, R. and M. Specht, A nomadic information system for adaptive exhibition guidance. Archives and museum informatics, 1999. 13(2): p. 127-138.

6. Hornecker, E. and M. Stifter. Learning from interactive museum installations about interaction design for public settings. in Proceedings of the 18th Australia conference on Computer-Human Interaction: Design: Activities, Artefacts and Environments. 2006. ACM.

7. Fraser, M., et al. Assembling history. in ECSCW 2003. 2003. Springer.

8. Hammady, R., M. Ma, and N. Temple. Augmented reality and gamification in heritage museums. in Joint International Conference on Serious Games. 2016. Springer.

9. Rubino, I., Step by Step: Exploring Heritage Through a Mobile Augmented Reality Application at Palazzo Madama-Museo Civico d'Arte Antica (Turin, Italy). 2013.

10. Fleck, M., et al. Rememberer: A tool for capturing museum visits. in International Conference on Ubiquitous Computing. 2002. Springer.

11. Screven, C.G., Information Design in Informal Settings Museums and Other Public Spaces. Information design, 2000: p. 131-192.

12. Zancanaro, M., O. Stock, and I. Alfaro, Using Cinematic Techniques in a Multimedia Museum Guide. 2003.

13. Zhang, S., et al. A mixed-reality museum tourism framework based on HMD and fisheye camera. in Proceedings of the 15th ACM SIGGRAPH Conference on Virtual-Reality Continuum and Its Applications in Industry-Volume 1. 2016. ACM.

14. Holz, T., et al. Mixed reality agents as museum guides. in ABSHL'06: Agent-Based Systems for Human Learning, AAMAS 2006 Workshop. 2006.

15. Bottino, A.G., A.M. García, and E. Occhipinti, Holomuseum: a prototype of interactive exhibition with Mixed Reality glasses HoloLens. 2017. 
16. Pollalis, C., et al. HoloMuse: Enhancing engagement with archaeological artifacts through gesture-based interaction with holograms. in Proceedings of the Tenth International Conference on Tangible, Embedded, and Embodied Interaction. 2017. ACM.

17. Ens, B. and P. Irani, Spatial Analytic Interfaces: Spatial User Interfaces for In Situ Visual Analytics. IEEE computer graphics and applications, 2017.37(2): p. 66-79.

18. Davis, F.D., R.P. Bagozzi, and P.R. Warshaw, User acceptance of computer technology: a comparison of two theoretical models. Management science, 1989. 35(8): p. 982-1003.

19. Card, S.K., J.D. Mackinlay, and B. Shneiderman, Readings in information visualization: using vision to think. 1999 : Morgan Kaufmann.

20. Weiser, M. and J.S. Brown, Designing calm technology. PowerGrid Journal, 1996. 1(1): p. 75-85.

21. Hallnäs, L. and J. Redström, From use to presence: on the expressions and aesthetics of everyday computational things. ACM Transactions on Computer-Human Interaction (TOCHI), 2002. 9(2): p. 106-124.

22. Ishii, H., S. Ren, and P. Frei. Pinwheels: visualizing information flow in an architectural space. in CHI'01 Extended Abstracts on Human Factors in Computing Systems. 2001. ACM.

23. Boehner, K., P. Sengers, and G. Gay, Affective presence in museums: Ambient systems for creative expression. Digital Creativity, 2005. 16(2): p. 79-89.

24. Danks, M., et al. Interactive storytelling and gaming environments for museums: The interactive storytelling exhibition project. in International Conference on Technologies for E-Learning and Digital Entertainment. 2007. Springer.

25. Mandler, J.M., Stories, scripts, and scenes: Aspects of schema theory. 2014: Psychology Press.

26. Falk, J.H. and L.D. Dierking, Learning from museums: Visitor experiences and the making of meaning. 2000: Altamira Press.

27. Giaccardi, E., Collective storytelling and social creativity in the virtual museum: a case study. Design Issues, 2006. 22(3): p. 29-41.

28. Taylor, E.W. and A.C. Neill, Museum education: A nonformal education perspective. Journal of Museum Education, 2008. 33(1): p. 23-32.

29. Zancanaro, M., et al., Children in the museum: an environment for collaborative storytelling, in PEACH-Intelligent Interfaces for Museum Visits. 2007, Springer. p. 165-184.

30. Rizvic, S., et al. Interactive digital storytelling in the sarajevo survival tools virtual environment. in Proceedings of the 28 th spring conference on computer graphics. 2013. ACM.

31. Sljivo, S. and S. Bosnia. Audio guided virtual museums. in Central European Seminar on Computer Graphics. 2012. Citeseer.

32. Rizvić, S., et al., Interactive storytelling about Isa Bey's endowment. 2014. 25: p. 66-74.

33. Sadzak, A., et al. Information perception in virtual heritage storytelling using animated and real avatars. in Spring Conference on Computer Graphics. 2007.

34. Rizvic, S., et al. Guidelines for interactive digital storytelling presentations of cultural heritage. in 20179 th International Conference on Virtual Worlds and Games for Serious Applications (VS-Games). 2017. IEEE.

35. Thompson, J.M.A., Manual of Curatorship: A Guide to Museum Practice. 2015: Taylor \& Francis.

36. Rocchi, C., et al. The museum visit: generating seamless personalized presentations on multiple devices. in Proceedings of the 9th international conference on Intelligent user interfaces. 2004. ACM.

37. Krüger, A., et al. M.: Seamless personalized TV-like presentations on mobile and stationary devices in a museum. in In: Proceedings of the International Conference on Hypermedia and Interactivity in Museums (ICHIM. 2003. Citeseer.

38. Raptis, D., N. Tselios, and N. Avouris, Context-based design of mobile applications for museums: a survey of existing practices, in Proceedings of the 7th international conference on Human computer interaction with mobile devices \&amp; services. 2005, ACM: Salzburg, Austria. p. 153-160.

39. Hornecker, E. "I don't understand it either, but it is cool"-visitor interactions with a multi-touch table in a museum. in Horizontal interactive human computer systems, 2008. TABLETOP 2008. 3rd IEEE International Workshop on. 2008. IEEE.

40. Geller, T., Interactive tabletop exhibits in museums and galleries. IEEE Computer Graphics and Applications, 2006. 26(5): p. 6-11.

41. Horn, M., et al. Of BATs and APEs: an interactive tabletop game for natural history museums. in Proceedings of the SIGCHI Conference on Human Factors in Computing Systems. 2012. ACM.

42. Swartout, W., et al. Ada and Grace: Toward realistic and engaging virtual museum guides. in Intelligent Virtual Agents. 2010. Springer.

43. Liarokapis, F., An augmented reality interface for visualizing and interacting with virtual content. Virtual Reality, 2007. 11(1): p. 23-43.

44. Boland, P. and C. Johnson, Archaeology as computer visualization: virtual tours of Dudley Castle c. 1550. British Museum Occasional Papers, 1996. 114: p. 227-233.

45. Milgram, P., et al., Augmented Reality: A class of displays on the reality-virtuality continuum. Telemanipulator and Telepresence Technologies, 1994. 2351.

46. Microsoft. Microsoft HoloLens. 2015; Available from: https://www.microsoft.com/en-us/hololens/buy.

47. Leap, M. Magic Leap. 2018; Available from: https://www.magicleap.com/.

48. Prasuethsut, L. Meta 2 first impressions: AR feels closer than ever. 2016 [cited 20172 April]; Available from: https://www.wareable.com/ar/meta-2-review.

49. Rekimoto, J. Matrix: a realtime object identification and registration method for augmented reality. in Computer Human Interaction, 1998. Proceedings. 3rd Asia Pacific. 1998.

50. Vlahakis, V., et al., Archeoguide: an augmented reality guide for archaeological sites. IEEE Computer Graphics and Applications, 2002(5): p. 52-60.

51. Damala, A. and N. Stojanovic. Tailoring the Adaptive Augmented Reality (A 2 R) museum visit: Identifying Cultural Heritage professionals' motivations and needs. in 2012 IEEE International Symposium on Mixed and Augmented RealityArts, Media, and Humanities (ISMAR-AMH). 2012. IEEE. 
52. Melnick, K. Art Exhibit Launches Virtual Museum Using Microsoft Hololens. 2017 [cited 2018 August].

53. Cortana, J. The Future of Holograms in Museums. 2017; Available from: https://www.cortinaproductions.com/hologramsin-museums/.

54. Raptis, G.E., C. Fidas, and N. Avouris. Cultural Heritage Gaming: Effects of Human Cognitive Styles on Players' Performance and Visual Behavior. in Adjunct Publication of the 25th Conference on User Modeling, Adaptation and Personalization. 2017. ACM.

55. Cavazza, M., et al., Multimodal acting in mixed reality interactive storytelling. 2004. 11(3): p. 30-39.

56. Nakevska, M., et al., Interactive storytelling in a mixed reality environment: the effects of interactivity on user experiences. Entertainment computing, 2017. 21: p. 97-104.

57. Hughes, C.E., et al. Augmenting museum experiences with mixed reality. in Proceedings of KSCE 2004. 2004.

58. Valtolina, S., A storytelling-driven framework for cultural heritage dissemination. Data Science Engineering, 2016. 1(2): p. 114-123.

59. Packer, J. and R. Ballantyne, Motivational factors and the visitor experience: A comparison of three sites. Curator: The Museum Journal, 2002. 45(3): p. 183-198.

60. De Luca, A., et al., The Illustrated Guide to the Egyptian Museum in Cairo. 2001: American University in Cairo Press.

61. Edwards, I.E.S., et al., Tutankhamun, His Tomb and Its Treasures. 1976: Metropolitan Museum of Art.

62. Hays, J. ANCIENT EGYPTIAN RELIGION, GODS, MYTHS AND SUPERSTITIONS. 20082012 [cited 2016; Available from: http://factsanddetails.com/world/cat55/sub350/item2317.html.

63. bestourism.com, Tutankhamun treasure. 2018.

64. Wojciechowski, R. and W. Cellary, Evaluation of learners' attitude toward learning in ARIES augmented reality environments. Computers \& Education, 2013. 68: p. 570-585.

65. Louho, R., M. Kallioja, and P. Oittinen, Factors affecting the use of hybrid media applications. Graphic arts in Finland, 2006. 35(3): p. 11-21.

66. Davis, F.D., Perceived usefulness, perceived ease of use, and user acceptance of information technology. MIS quarterly, 1989: p. 319-340.

67. Rasimah, C.M.Y., A. Ahmad, and H.B. Zaman, Evaluation of user acceptance of mixed reality technology. Australasian Journal of Educational Technology, 2011. 27(8).

68. King, W.R. and J. He, A meta-analysis of the technology acceptance model. Information \& management, 2006. 43(6): p. 740-755.

69. Williams, T., et al. Virtual, Augmented, and Mixed Reality for Human-Robot Interaction. in Companion of the 2018 ACM/IEEE International Conference on Human-Robot Interaction. 2018. ACM

70. tom Dieck, M.C. and T. Jung, A theoretical model of mobile augmented reality acceptance in urban heritage tourism. Current Issues in Tourism, 2018. 21(2): p. 154-174.

71. Haugstvedt, A.-C. and J. Krogstie. Mobile augmented reality for cultural heritage: A technology acceptance study. in Mixed and Augmented Reality (ISMAR), 2012 IEEE International Symposium on. 2012. IEEE.

72. Kalantari, M. and P. Rauschnabel, Exploring the early adopters of augmented reality smart glasses: The case of Microsoft HoloLens, in Augmented Reality and Virtual Reality. 2018, Springer. p. 229-245.

73. Rauschnabel, P.A. and Y.K. Ro, Augmented reality smart glasses: An investigation of technology acceptance drivers. International Journal of Technology Marketing, 2016. 11(2): p. 123-148.

74. tom Dieck, D., et al., Tourists' virtual reality adoption: an exploratory study from Lake District National Park. Leisure Studies, 2018: p. 1-13.

75. Fishbein, M. and I. Ajzen, Belief, attitude, intention, and behavior: An introduction to theory and research. 1977.

76. Van Raaij, E.M. and J.J. Schepers, The acceptance and use of a virtual learning environment in China. Computers \& Education, 2008. 50(3): p. 838-852.

77. Davis, F.D., User acceptance of information technology: system characteristics, user perceptions and behavioral impacts. International journal of man-machine studies, 1993. 38(3): p. 475-487.

78. Agarwal, R. and J. Prasad, A conceptual and operational definition of personal innovativeness in the domain of information technology. Information systems research, 1998. 9(2): p. 204-215.

79. Lu, J., J.E. Yao, and C.-S. Yu, Personal innovativeness, social influences and adoption of wireless Internet services via mobile technology. The Journal of Strategic Information Systems, 2005. 14(3): p. 245-268.

80. Rogers, E., Diffusion of Innovations (4th Eds.) ACM The Free Press (Sept. 2001). New York, 1995: p. 15-23.

81. Choi, H., J. Park, and S. Park, A study on the effect of mobile tourism information services on tourist satisfaction and continual reuse. International Journal of Business Information Technology, 2011. 1(3): p. 189-195.

82. Jung, T., N. Chung, and M.C. Leue, The determinants of recommendations to use augmented reality technologies: The case of a Korean theme park. Tourism management, 2015. 49: p. 75-86.

83. Parveen, F. and A. Sulaiman, Technology complexity, personal innovativeness and intention to use wireless internet using mobile devices in Malaysia. International Review of Business Research Papers, 2008. 4(5): p. 1-10.

84. Hwang, Y., User experience and personal innovativeness: An empirical study on the Enterprise Resource Planning systems. Computers in Human Behavior, 2014. 34: p. 227-234.

85. Lee, S.M., et al., The role of exogenous factors in technology acceptance: The case of object-oriented technology. Information

Management 2006. 43(4): p. 469-480.

86. Davis, F.D., R.P. Bagozzi, and P.R. Warshaw, Extrinsic and intrinsic motivation to use computers in the workplace 1. Journal of applied social psychology, 1992. 22(14): p. 1113.

87. Chesney, T., An acceptance model for useful and fun information systems. Human Technology: An Interdisciplinary Journal on Humans in ICT Environments, 2006.

88. Serenko, A., A model of user adoption of interface agents for email notification. Interacting with Computers, 2008. 20(45): p. 461-472. 
89. Mun, Y.Y. and Y. Hwang, Predicting the use of web-based information systems: self-efficacy, enjoyment, learning goal orientation, and the technology acceptance model. International journal of human-computer studies, 2003. 59(4): p. 431449.

90. Heerink, M., et al. Enjoyment intention to use and actual use of a conversational robot by elderly people. in Proceedings of the 3rd ACM/IEEE international conference on Human robot interaction. 2008. ACM.

91. Sun, H. and P. Zhang, Causal relationships between perceived enjoyment and perceived ease of use: An alternative approach. Journal of the Association for Information Systems, 2006. 7(1): p. 24.

92. Venkatesh, V., et al., User acceptance of information technology: Toward a unified view. MIS quarterly, 2003: p. 425478.

93. Luarn, P. and H.-H. Lin, Toward an understanding of the behavioral intention to use mobile banking. Computers in human behavior, 2005. 21(6): p. 873-891.

94. Lin, J.C.-C. and H. Lu, Towards an understanding of the behavioural intention to use a web site. International journal of information management, 2000. 20(3): p. 197-208.

95. $\mathrm{Xu}, \mathrm{H}$. and $\mathrm{S}$. Gupta, The effects of privacy concerns and personal innovativeness on potential and experienced customers' adoption of location-based services. Electronic Markets, 2009. 19(2-3): p. 137-149.

96. Fogg, B., et al. What makes Web sites credible?: a report on a large quantitative study. in Proceedings of the SIGCHI conference on Human factors in computing systems. 2001. ACM.

97. Mahat, J., A.F.M. Ayub, and S. Luan, An assessment of students' mobile self-efficacy, readiness and personal innovativeness towards mobile learning in higher education in Malaysia. Procedia-Social

Behavioral Sciences, 2012. 64: p. 284-290.

98. Owen, R., D. Buhalis, and D. Pletinckx. Visitors' Evaluations of ICTs Used in Cultural Heritage. in Vast. 2005. Citeseer.

99. Disztinger, P., S. Schlögl, and A. Groth, Technology acceptance of virtual reality for travel planning, in Information and Communication Technologies in Tourism 2017. 2017, Springer. p. 255-268. 


\section{Appendix}

Table 1. Intention to experience a new system variable

$(1=$ Strongly disagree to $5=$ Strongly agree. $\mathrm{N}=47)$

\begin{tabular}{|c|c|c|c|c|c|c|c|}
\hline Measure & $\begin{array}{c}\text { Strongly } \\
\text { agree }\end{array}$ & Agree & Neutral & Disagree & $\begin{array}{c}\text { Strongly } \\
\text { disagree }\end{array}$ & Mean & $\begin{array}{c}\text { Std. } \\
\text { Dev. }\end{array}$ \\
\hline $\begin{array}{c}\text { (PI1) } \\
\text { Excited to try new experience }\end{array}$ & $\begin{array}{c}57.4 \% \\
(27)\end{array}$ & $\begin{array}{c}40.4 \% \\
(19)\end{array}$ & $\begin{array}{c}2.1 \% \\
(1)\end{array}$ & $\begin{array}{c}0.0 \% \\
(0)\end{array}$ & $\begin{array}{c}0.0 \% \\
(0)\end{array}$ & 4.55 & .544 \\
\hline $\begin{array}{c}\text { (PI2) } \\
\text { Happy to wear cutting edge headset }\end{array}$ & $\begin{array}{c}61.7 \% \\
(29)\end{array}$ & $\begin{array}{c}36.2 \% \\
(17)\end{array}$ & $\begin{array}{c}2.1 \% \\
(1)\end{array}$ & $\begin{array}{c}0.0 \% \\
(0)\end{array}$ & $\begin{array}{c}0.0 \% \\
(0)\end{array}$ & 4.60 & .538 \\
\hline $\begin{array}{c}\text { (PI3) } \\
\text { Don't feel hesitated to try new } \\
\text { technology }\end{array}$ & $\begin{array}{c}68.1 \% \\
(32)\end{array}$ & $\begin{array}{c}29.8 \% \\
(14)\end{array}$ & $\begin{array}{c}2.1 \% \\
(1)\end{array}$ & $\begin{array}{c}0.0 \% \\
(0)\end{array}$ & $\begin{array}{c}0.0 \% \\
(0)\end{array}$ & 4.66 & .522 \\
\hline $\begin{array}{c}\text { (PI4) } \\
\text { Interested to see something unusual }\end{array}$ & $\begin{array}{c}53.2 \% \\
(25)\end{array}$ & $\begin{array}{c}44.7 \% \\
(21)\end{array}$ & $\begin{array}{c}2.1 \% \\
(1)\end{array}$ & $\begin{array}{c}0.0 \% \\
(0)\end{array}$ & $\begin{array}{c}0.0 \% \\
(0)\end{array}$ & 4.51 & .547 \\
\hline
\end{tabular}

Table 2. Enjoyment variable

$(1=$ Strongly disagree to $5=$ Strongly agree. $\mathrm{N}=47)$

\begin{tabular}{|c|c|c|c|c|c|c|c|}
\hline Measure & $\begin{array}{c}\text { Strongly } \\
\text { agree }\end{array}$ & Agree & Neutral & Disagree & $\begin{array}{c}\text { Strongly } \\
\text { disagree }\end{array}$ & Mean & $\begin{array}{c}\text { Std. } \\
\text { Dev. }\end{array}$ \\
\hline $\begin{array}{c}\text { (ENJ1) } \\
\text { I was unhappy when the scene } \\
\text { finished }\end{array}$ & $\begin{array}{c}14.9 \% \\
(7)\end{array}$ & $\begin{array}{c}57.4 \% \\
(27)\end{array}$ & $\begin{array}{c}27.7 \% \\
(13)\end{array}$ & $\begin{array}{c}0.0 \% \\
(0)\end{array}$ & $\begin{array}{c}0.0 \% \\
(0)\end{array}$ & 3.87 & .647 \\
\hline $\begin{array}{c}\text { (ENJ2) } \\
\text { The battle was exciting }\end{array}$ & $\begin{array}{c}12.8 \% \\
(6)\end{array}$ & $\begin{array}{c}61.7 \% \\
(26)\end{array}$ & $\begin{array}{c}25.5 \% \\
(12)\end{array}$ & $\begin{array}{c}0.0 \% \\
(0)\end{array}$ & $0.0 \%$ & 3.87 & .612 \\
\hline $\begin{array}{c}\text { (ENJ3) } \\
\text { I enjoyed watching characters and } \\
\text { listening to music }\end{array}$ & $\begin{array}{c}17.0 \% \\
(9)\end{array}$ & $\begin{array}{c}59.6 \% \\
(28)\end{array}$ & $\begin{array}{c}23.4 \% \\
(11)\end{array}$ & $\begin{array}{c}0.0 \% \\
(0)\end{array}$ & $\begin{array}{c}0.0 \% \\
(0)\end{array}$ & 3.94 & .639 \\
\hline $\begin{array}{c}\text { (ENJ4) } \\
\text { I felt I was in the battle arena and so } \\
\text { immersed }\end{array}$ & $\begin{array}{c}19.1 \% \\
(9)\end{array}$ & $\begin{array}{c}57.4 \% \\
(27)\end{array}$ & $\begin{array}{c}23.4 \% \\
(11)\end{array}$ & $\begin{array}{c}0.0 \% \\
(0)\end{array}$ & $\begin{array}{c}0.0 \% \\
(0)\end{array}$ & 3.96 & .658 \\
\hline $\begin{array}{c}\text { (ENJ5) } \\
\text { I was so engaged and I felt I was in } \\
\text { the middle of the Battle }\end{array}$ & $\begin{array}{c}19.1 \% \\
(9)\end{array}$ & $\begin{array}{c}61.7 \% \\
(29)\end{array}$ & $\begin{array}{c}19.1 \% \\
(9)\end{array}$ & $\begin{array}{c}0.0 \% \\
(0)\end{array}$ & $\begin{array}{c}0.0 \% \\
(0)\end{array}$ & 4.00 & .626 \\
\hline
\end{tabular}

Table 3. Ease of use variable

$(1=$ Strongly disagree to $5=$ Strongly agree. $\mathrm{N}=47)$

\begin{tabular}{|c|c|c|c|c|c|c|c|}
\hline Measure & $\begin{array}{c}\text { Strongly } \\
\text { agree }\end{array}$ & Agree & Neutral & Disagree & $\begin{array}{c}\text { Strongly } \\
\text { disagree }\end{array}$ & Mean & $\begin{array}{c}\text { Std. } \\
\text { Dev. }\end{array}$ \\
\hline $\begin{array}{c}\text { (EOU1) } \\
\text { It was easy to explore environment } \\
\text { and watch the battle }\end{array}$ & $\begin{array}{c}57.4 \% \\
(27)\end{array}$ & $\begin{array}{c}42.6 \% \\
(20)\end{array}$ & $\begin{array}{c}0.0 \% \\
(0)\end{array}$ & $\begin{array}{c}0.0 \% \\
(0)\end{array}$ & $\begin{array}{c}0.0 \% \\
(0)\end{array}$ & 4.57 & .500 \\
\hline $\begin{array}{c}\text { (EOU2) } \\
\text { It would be easy for me to become } \\
\text { skilful at using the application }\end{array}$ & $\begin{array}{c}61.7 \% \\
(29)\end{array}$ & $\begin{array}{c}38.3 \% \\
(18)\end{array}$ & $\begin{array}{c}0.0 \% \\
(0)\end{array}$ & $\begin{array}{c}0.0 \% \\
(0)\end{array}$ & $\begin{array}{c}0.0 \% \\
(0)\end{array}$ & 4.62 & .491 \\
\hline $\begin{array}{c}\text { (EOU3) } \\
\text { I can easily use the app without help }\end{array}$ & $\begin{array}{c}63.8 \% \\
(30)\end{array}$ & $\begin{array}{c}36.2 \% \\
(17)\end{array}$ & $\begin{array}{c}0.0 \% \\
(0)\end{array}$ & $\begin{array}{c}0.0 \% \\
(0)\end{array}$ & $\begin{array}{c}0.0 \% \\
(0)\end{array}$ & 4.64 & .486 \\
\hline $\begin{array}{c}\text { (EOU4) } \\
\text { I could do air tap }\end{array}$ & $\begin{array}{c}68.1 \% \\
(32)\end{array}$ & $\begin{array}{c}31.9 \% \\
(15)\end{array}$ & $\begin{array}{c}0.0 \% \\
(0)\end{array}$ & $\begin{array}{c}0.0 \% \\
(0)\end{array}$ & $\begin{array}{c}0.0 \% \\
(0)\end{array}$ & 4.68 & .471 \\
\hline
\end{tabular}


Table 4. Usefulness variable

$(1=$ Strongly disagree to $5=$ Strongly agree. $\mathrm{N}=47)$

\begin{tabular}{|c|c|c|c|c|c|c|c|}
\hline Measure & $\begin{array}{c}\text { Strongly } \\
\text { agree }\end{array}$ & Agree & Neutral & Disagree & $\begin{array}{l}\text { Strongly } \\
\text { disagree }\end{array}$ & Mean & $\begin{array}{l}\text { Std. } \\
\text { Dev. }\end{array}$ \\
\hline $\begin{array}{c}\text { (USF1) } \\
\text { The battle enhanced my } \\
\text { understanding of historical wars }\end{array}$ & $\begin{array}{c}57.4 \% \\
(27)\end{array}$ & $\begin{array}{c}40.4 \% \\
(19)\end{array}$ & $\begin{array}{c}2.1 \% \\
(1)\end{array}$ & $\begin{array}{c}0.0 \% \\
(0)\end{array}$ & $\begin{array}{c}0.0 \% \\
(0)\end{array}$ & 4.55 & .544 \\
\hline $\begin{array}{l}\text { (USF2) } \\
\text { I believe this technology is useful in } \\
\text { learning and education }\end{array}$ & $\begin{array}{c}55.3 \% \\
(26)\end{array}$ & $\begin{array}{c}40.4 \% \\
(19)\end{array}$ & $\begin{array}{c}4.3 \% \\
(2)\end{array}$ & $\begin{array}{c}0.0 \% \\
(0)\end{array}$ & $\begin{array}{c}0.0 \% \\
(0)\end{array}$ & 4.51 & .585 \\
\hline $\begin{array}{c}\text { (USF3) } \\
\text { This technology is able to visualise } \\
\text { historical stories }\end{array}$ & $\begin{array}{c}63.8 \% \\
(30)\end{array}$ & $\begin{array}{c}34.0 \% \\
(16)\end{array}$ & $\begin{array}{c}2.1 \% \\
(1)\end{array}$ & $\begin{array}{c}0.0 \% \\
(0)\end{array}$ & $\begin{array}{c}0.0 \% \\
(0)\end{array}$ & 4.62 & .534 \\
\hline $\begin{array}{l}\text { (USF4) } \\
\text { This technology is useful in } \\
\text { museums to enrich the museum } \\
\text { experience }\end{array}$ & $\begin{array}{c}55.3 \% \\
(26)\end{array}$ & $\begin{array}{c}40.4 \% \\
(19)\end{array}$ & $\begin{array}{c}4.3 \% \\
(2)\end{array}$ & $\begin{array}{c}0.0 \% \\
(0)\end{array}$ & $\begin{array}{c}0.0 \% \\
(0)\end{array}$ & 4.51 & .585 \\
\hline
\end{tabular}

Table 5. The willingness of future use variable

( 1 = Strongly disagree to $5=$ Strongly agree. $\mathrm{N}=47$ )

\begin{tabular}{|c|c|c|c|c|c|c|c|}
\hline Measure & $\begin{array}{l}\text { Strongly } \\
\text { agree }\end{array}$ & Agree & Neutral & Disagree & $\begin{array}{l}\text { Strongly } \\
\text { disagree }\end{array}$ & Mean & $\begin{array}{l}\text { Std. } \\
\text { Dev. }\end{array}$ \\
\hline $\begin{array}{c}\text { (WFU1) } \\
\text { If I know it is available, I would use } \\
\text { it }\end{array}$ & $\begin{array}{c}23.4 \% \\
(37)\end{array}$ & $\begin{array}{c}59.6 \% \\
(10)\end{array}$ & $\begin{array}{c}0.0 \% \\
(0)\end{array}$ & $\begin{array}{c}0.0 \% \\
(0)\end{array}$ & $\begin{array}{c}0.0 \% \\
(0)\end{array}$ & 4.79 & 0.414 \\
\hline $\begin{array}{c}(\text { WFU2) } \\
\text { I wish to cover more stories }\end{array}$ & $\begin{array}{c}25.5 \% \\
(38)\end{array}$ & $\begin{array}{c}59.6 \% \\
(9)\end{array}$ & $\begin{array}{c}0.0 \% \\
(0)\end{array}$ & $\begin{array}{c}2.1 \% \\
(1)\end{array}$ & $\begin{array}{c}0.0 \% \\
(0)\end{array}$ & 4.81 & 0.398 \\
\hline $\begin{array}{c}\text { (WFU3) } \\
\text { I intend to use similar applications } \\
\text { like 'The Battle' }\end{array}$ & $\begin{array}{c}31.9 \% \\
(41)\end{array}$ & $\begin{array}{c}51.1 \% \\
(6)\end{array}$ & $\begin{array}{c}0.0 \% \\
(0)\end{array}$ & $\begin{array}{c}0.0 \% \\
(0)\end{array}$ & $\begin{array}{c}0.0 \% \\
(0)\end{array}$ & 4.87 & 0.337 \\
\hline $\begin{array}{l}\text { (WFU4) } \\
\text { If the museum makes it available, I } \\
\text { would pay to rent it }\end{array}$ & $\begin{array}{c}31.9 \% \\
(41)\end{array}$ & $\begin{array}{c}51.1 \% \\
(6)\end{array}$ & $\begin{array}{l}0.0 \% \\
(0)\end{array}$ & $\begin{array}{c}0.0 \% \\
(0)\end{array}$ & $\begin{array}{l}0.0 \% \\
(0)\end{array}$ & 4.87 & 0.337 \\
\hline
\end{tabular}

